\title{
Cooperativismo solidário: um estudo de caso da Cooperativa Cores da Terra na ótica
} da análise SWOT

\author{
Solidarity cooperativism: a case study of the Cores da Terra Cooperative from the perspective of \\ SWOT analysis
}

Cooperativismo solidario: un estudio de caso de la Cooperativa Cores da Terra desde la perspectiva del análisis DAFO

Recebido: 03/08/2021 | Revisado: 09/08/2021 | Aceito: 11/08/2021 | Publicado: 15/08/2021

\author{
Simone Cesario Soares \\ ORCID: https://orcid.org/0000-0002-4219-5729 \\ Universidade Estadual do Oeste do Paraná, Brasil \\ E-mail: ccsimone@hotmail.com \\ Dariny Christina Dutra Schoder Bonato \\ ORCID: https://orcid.org/0000-0002-6317-9373 \\ Universidade Estadual do Oeste do Paraná, Brasil \\ E-mail: daryschoder@hotmail.com \\ Maria Vitória Fontolan \\ ORCID: https://orcid.org/0000-0002-8057-6442 \\ Universidade Estadual do Oeste do Paraná, Brasil \\ E-mail: mvfontolan@gmail.com \\ Elaine de Oliveira Zanini \\ ORCID: https://orcid.org/0000-0002-5098-7857 \\ Universidade Estadual do Oeste do Paraná, Brasil \\ E-mail: elainezanini@gmail.com \\ Wilson João Zonin \\ ORCID: https://orcid.org/0000-0002-3364-5599 \\ Universidade Estadual do Oeste do Paraná, Brasil \\ E-mail: wzonin@yahoo.com.br
}

\begin{abstract}
Resumo
O presente artigo buscou retratar o trabalho realizado pela Cooperativa Cores da Terra, certificada pela Certificação Orgânicos Brasil, e localizada na cidade de Cascavel, oeste paranaense. O trabalho foi realizado a partir do estudo do caso, analisando o cenário estratégico da cooperativa de acordo com os conceitos da ferramenta SWOT. A cooperativa produz e comercializa seus produtos orgânicos, por meio da agricultura familiar. Neste contexto, a atividade agrícola, baseada no cooperativismo, se diferencia das demais, por seu caráter solidário, organizacional, econômico, coletivo, colaborativo e baseado na sustentabilidade rural. Ao mesmo tempo a produção orgânica e agroecológica, tem se tornado aliada estratégica, quando se trata da qualidade de vida, oportunizando aos consumidores, bem como aos produtores, uma vida mais saudável e com menos agrotóxicos. Concluiu-se com a pesquisa, que esta experiência de economia solidária e agroecológica formata novos desenhos de mercado agroecológico, com consciência socioambiental, ao mesmo tempo em que busca uma relação ética entre produtores e consumidores, com a construção de um mercado justo e na promoção da segurança alimentar e nutricional.
\end{abstract}

Palavras-chave: Análise SWOT; Cooperativismo Solidário; Agricultura Familiar.

\begin{abstract}
The present article sought to portray the work done by the Cores da Terra Cooperative, certified by Organic Certification Brazil, and located in the city of Cascavel, west of Paraná. The work was carried out from the case study, analyzing the strategic scenario of the cooperative according to the concepts of the SWOT tool. The cooperative produces and sells its organic products through family agriculture. In this context, the agricultural activity, based on cooperativism, is different from the others, for its solidary, organizational, economic, collective, collaborative character, and based on rural sustainability. At the same time, organic and agroecological production has become a strategic ally when it comes to quality of life, providing consumers, as well as producers, with a healthier life, with less agrochemicals. The research concluded that this experience of solidarity economy and agroecology forms new agroecological market designs, with socio-environmental awareness, while seeking an ethical relationship between producers and consumers, with the construction of a fair market and the promotion of food and nutritional security.
\end{abstract}

Keywords: SWOT Analysis; Solidarity Cooperatives; Family Farming. 


\begin{abstract}
Resumen
Este artículo pretendía retratar el trabajo realizado por la Cooperativa Cores da Terra, certificada por Certificación Orgánica Brasil, y situada en la ciudad de Cascavel, al oeste de Paraná. El trabajo se realizó a partir del estudio del caso, analizando el escenario estratégico de la cooperativa según los conceptos de la herramienta DAFO. La cooperativa produce y vende sus productos ecológicos a través de la agricultura familiar. En este contexto, la actividad agraria, basada en el cooperativismo, se diferencia de las demás, por su carácter solidario, organizativo, económico, colectivo, colaborativo y basado en la sostenibilidad rural. Al mismo tiempo, la producción orgánica y agroecológica se ha convertido en un aliado estratégico cuando se trata de la calidad de vida, proporcionando a los consumidores, así como a los productores, una vida más saludable y menos pesticidas. La investigación concluyó que esta experiencia de economía solidaria y agroecológica conforma nuevos diseños de mercado agroecológico, con conciencia social y ambiental, buscando una relación ética entre productores y consumidores, con la construcción de un mercado justo y la promoción de la seguridad alimentaria y nutricional.
\end{abstract}

Palabras clave: Análisis DAFO; Cooperativas Solidarias; Agricultura Familiar.

\title{
1. Introdução
}

A agricultura familiar é uma das responsáveis pela produção de alimentos para os brasileiros. Fazem parte deste grupo: pequenos produtores rurais, comunidades quilombolas, assentamentos de reforma agrária, extrativistas, pescadores entre outros. Este setor se destaca pela produção de diversos gêneros alimentares, como milho, mandioca, feijão, arroz entre outros. Segundo a Organização das Nações Unidas (2019), os agricultores familiares são essenciais para a subsistência global, podendo ser considerados atores socioeconômicos vitais para apoiar melhores meios de subsistência, criação de empregos, e desenvolvimento rural.

Nesta perspectiva o cooperativismo solidário pode ser considerado um alicerce para o agricultor familiar, na medida em que oferece oportunidades empreendedoras mais seguras e organizadas. Ele possibilita ao pequeno agricultor trabalhar em conjunto se associando a outros produtores e assim conseguindo preços melhores, melhor renda e por consequência melhores condições de vida.

A Cooperativa de pequenos agricultores é uma solução para que eles comercializem com mais segurança, conheçam novas tecnologias, e formas mais fáceis, práticas e seguras de produzir.

Sendo assim, o objetivo deste artigo é retratar o trabalho realizado pela Cooperativa Cores da Terra, certificada pela Certificação Orgânicos Brasil, e localizada na cidade de Cascavel, oeste paranaense. O trabalho foi realizado através de estudo do caso interdisciplinar, analisando o cenário estratégico da cooperativa de acordo com os conceitos da ferramenta SWOT, para verificar os pontos fortes, fracos, possíveis ameaças e oportunidades da Cooperativa.

\section{Metodologia}

Os métodos delineados para a pesquisa estão descritos nesta seção. Este artigo caracteriza-se como pesquisa exploratória, uma vez que, objetiva maior familiaridade com o tema estudado, assim, foi possível analisar o cenário estratégico da cooperativa de acordo com os conceitos da ferramenta SWOT.

Para Marconi e Lakatos (2004), a pesquisa exploratória descreve as características dos fenômenos e estabelece relações entre atributos do ambiente interno e externo na cooperativa, caracterizando-se também como pesquisa descritiva, juntas elas descrevem completamente determinado fenômeno.

O trabalho se caracteriza como um estudo de caso, para Yin (2001), o estudo de caso é uma estratégia que contém muitas das técnicas usadas em pesquisas históricas, porém adiciona a observação do objeto de estudo e entrevistas. Para o autor Gil (2010), ele permite uma análise profunda, possibilitando o conhecimento amplo e específico do objeto de estudo. Em relação aos resultados apresentados, a pesquisa caracteriza-se como uma pesquisa qualitativa, pois visa analisar e revelar quais são as oportunidades e desafios da Cooperativa Cores da Terra em relação ao seu ambiente interno e externo. 
A perspectiva do estudo foi à realização de uma prática interdisciplinar, onde se buscou a convergência de diferentes olhares para a compreensão do processo que envolve a produção de comercialização de produtos agroecologicos (Zonin; Neukirchen, 2020).

Uma das técnicas utilizadas para levantamento de dados foi à entrevista, ela possibilita o esclarecimento sobre o assunto estudado e flexibiliza a adaptação às circunstâncias da entrevista ao pesquisador (Gil, 2010). O tipo de entrevista semiestruturada ocorre diante de um roteiro com o propósito de obter informações detalhadas sobre tema específico, permitindo inserir questões, cujas respostas trazem informações incrementais (Martins; Theóphilo, 2009).

Desse modo, o levantamento dos dados necessários para o estudo foi realizado por meio de três entrevistas semiestruturadas, concedidas pela gestora administrativa da Cooperativa Silvana Prestes Campos. Elas ocorreram de forma remota, nos dias 16 e 29 de maio de 2020 (via contato telefônico e aplicativo WhattsApp, respectivamente) e de forma presencial no dia 12 de maio de 2021. Nas entrevistas foi relatado com detalhes a complexidade do funcionamento da cooperativa e expostos os atributos relacionados à matriz SWOT.

Assim, a análise SWOT foi realizada a partir da interpretação dos autores sobre os dados fornecidos nas entrevistas. Elaborada a matriz SWOT e extraídos os resultados, ambos foram enviados para aprovação da Silvana, os quais tiveram feedback positivo.

\section{Resultados e Discussão}

\subsection{Agricultura Familiar}

A agricultura familiar era caracterizada como: agricultura de subsistência, pequena produção ou ainda pobreza rural. Somente nos anos de 1990, este segmento foi reconhecido como importante para o desenvolvimento do país (Guanziroli; Cardim, 2000).

A partir desta década agricultura familiar no Brasil, passa a ser conhecida enquanto de caráter social e produtiva, com a criação de políticas públicas. Até este momento as políticas públicas eram direcionadas apenas as grandes e médias propriedades (Esquerda-Souza; Bergamasco, 2015).

Conforme a Lei Federal de n. ${ }^{\circ} 11.326$, de 24 de julho de 2006, no artigo $3^{\circ}$, são características essenciais para se enquadrar como agricultores familiares: (i) não possuir área maior do que quatro módulos fiscais; (ii) a mão de obra utilizada nas atividades econômicas ser predominantemente familiar e (iii) o maior percentual da renda ser obtido das atividades econômicas do estabelecimento (Brasil, 2006).

Deste modo a agricultura familiar é caracterizada pela forma de gestão realizada por indivíduos que tem entre si laços de sangue ou de casamento, no entanto ela não é a única, essa caracterização é usada para obtenção de linha de crédito. De uma forma geral precisam apresentar três atributos básicos: gestão, propriedade e trabalho familiar (Abramovay, 2007, p. 03).

Conceitualmente o caráter da agricultura familiar, se dá no processo de execução onde é necessário pelo menos um membro da família, conforme esclarece Abramovay (2007):

A agricultura familiar é aquela em que a gestão, a propriedade e a maior parte do trabalho, vêm de indivíduos que mantêm entre si laços de sangue ou de casamento. Que esta definição não seja unânime e muitas vezes tampouco operacional. É perfeitamente compreensível, já que os diferentes setores sociais e suas representações constroem categorias científicas que servirão a certas finalidades práticas: a definição de agricultura familiar, para fins de atribuição de crédito, pode não ser exatamente a mesma daquela estabelecida com finalidades de quantificação estatística num estudo acadêmico. O importante é que estes três atributos básicos (gestão, propriedade e trabalho familiar) estão presentes em todas elas (Abramovay, 2007, p. 03). 
A renda da família pode vir exclusivamente da agricultura familiar, ou de outros membros da família, pode exercer atividades não agrícolas, está é uma tendência evidente, uma vez que há certa dinamicidade de produção na unidade familiar.

Lamarche (1993, p. 19), afirma que "os agricultores organizam suas lutas, suas estratégias, fazem alianças, na busca por preservar sua história e projetando seu futuro". Este universo composto por grupos muito peculiares, que criam estratégias próprias para sobrevivência. Não se pode afirmar que os agricultores familiares são grupos homogêneos e com perfil de produção estável.

Comumente a agricultura familiar é caracterizada como setor atrasado tecnológico e socialmente, produtor de alimentos básicos, visto apenas como agricultura de subsistência. Segundo Lamarche (1993, p. 24), "está é uma imagem estereotipada, e não corresponde à realidade".

Conforme dados do censo agropecuário de 2006, foram registrados 4.367 .902 estabelecimentos de agricultores familiares, 84,4\% dos estabelecimentos brasileiros, ocupando uma área de 80,25 milhões de hectares, ou seja, 24,3\% da área ocupada pelos estabelecimentos agropecuários brasileiros e são responsáveis por 38\% do Valor Bruto da Produção (MDA, 2006; Plein; Filippi, 2011; Paula et al., 2014), ou seja, o agricultor familiar corresponde a 10\% do Produto Interno Bruto (PIB), $38 \%$ do Valor Bruto da Produção Agropecuária (MDA, 2014).

Apesar da importante participação econômica dos agricultores familiares no PIB brasileiro, estes vivenciam muitos problemas no desenvolvimento da atividade rural. O que pode ser evidenciado pela pouca área de terra, baixa disponibilidade de recursos financeiros, sejam eles advindos de políticas governamentais ou da iniciativa privada, dificuldade de assistência técnica ou atividades de extensão rural, logística, a falta de processos artesanais de produção de alimentos, dificuldades de acesso ao mercado. Estas questões entre outras são fatores limitadores aos produtores de pequeno porte, dificultando sua competitividade no mercado (Paula et al., 2014).

Algumas políticas públicas foram implementadas, neste segmento no Brasil, com a criação dos programas, tais como: PRONAF (Programa Nacional de Fortalecimento da Agricultura Familiar), PAA (Programa de Aquisição de Alimentos) e o PNAE (Programa Nacional de Alimentação Escolar) (Pereira; Nascimento, 2014). A criação de programas governamentais é extremamente importante, não apenas no contexto econômico, mas também social, uma vez que fortalece os agricultores familiares, e melhora a qualidade de vida no meio rural.

\subsection{Agroecologia e a Produção Orgânica no Brasil}

A agroecologia é "uma nova abordagem que integra os princípios agronômicos, ecológicos e socioeconômicos, à compreensão e avaliação do efeito das tecnologias sobre os sistemas agrícolas e a sociedade como um todo" (Altieri, 2004, p. 23).

Segundo Caporal (2009), agroecologia pode ser entendida como:

[...] um enfoque científico que oferece os princípios e metodologias para apoiar a transição do atual modelo de desenvolvimento rural e de agricultura convencionais para estilos de desenvolvimento rural e de agricultura sustentáveis, buscando, num horizonte temporal, a construção de novos saberes socioambientais que alimentem um processo de transição agroecológica (Caporal, 2009. p. 220).

Assim, a agroecologia vai muito além da não utilização de agrotóxicos ou fertilizantes químicos. Ela é uma ciência interdisciplinar que visa uma perspectiva ecológica e sustentável para o desenvolvimento rural e agricultura, de modo a proporcionar alimentos com elevada qualidade biológica (Caporal; Costabeber, 2004).

A agroecologia está diretamente ligada à agricultura familiar e, consequentemente, ao desenvolvimento rural sustentável. Altieri (2012) entende que a agricultura familiar camponesa, que segue princípios agroecológicos, deve ser vista como patrimônio ecológico planetário, pois as pequenas propriedades rurais são de extrema importância, uma vez que elas 
representam uma possibilidade de produzir e consumir de forma mais saudável, conforme aponta Altieri: a) são a chave para a segurança alimentar mundial; b) são mais produtivas e conservam mais os recursos naturais do que monoculturas; c) representam modelos de sustentabilidade; d) representam um santuário de agrobiodiversidade livre de organismo geneticamente modificados, e; e) resfriam o clima.

Para Zonin e Brandenburg (2012) a transição agroecológica é um processo complexo, que não se limita apenas a dimensão técnica ou ecológica, mas engloba fatores sociais, econômicos e culturais, bem como as dimensões, políticas e de movimentos socioecológicos, (Zonin, 2007).

A transição agroecológica é o processo de "ecologização das agriculturas", que envolve as mudanças técnicas no manejo dos agrossistemas, bem como, mudanças sociais, considerando as ações desenvolvidas pelos agricultores e suas organizações, redesenhando a produção e o consumo, na busca de viabilizar um novo projeto de agricultura e desenvolvimento rural (Zonin; Brandenburg, 2012, p. 234).

Em síntese, os autores abordam três modalidades de transição agroecológica. A primeira, transição agroecológica de autoconsumo, traz a ideia de diversificação da produção e abastecimento da família. A segunda, transição agroecológica na modalidade orgânica, caracteriza-se pela vinculação a empresas. Por fỉm, a transição agroecológica Ecovida é caracterizada pela certificação participativa e pela relação direta com o consumidor (Zonin; Brandenburg, 2012).

Diante disso, partindo do pressuposto que a agroecologia é uma ciência usada como base principiológica para diversos sistemas agropecuários, faz-se necessário entender a conceituação de agricultura orgânica e como ela se compreende e desenvolve no Brasil.

De acordo com Moura (2017):

[...] a agricultura orgânica é uma pratica agrícola que tem por princípio estabelecer sistemas de produção baseados em conjuntos de procedimentos que envolvem a planta, o solo e as condições climáticas, de forma a produzir um alimento sadio, livre de contaminantes químicos e agrotóxicos. (Moura, 2017, p. 26)

No Brasil a produção orgânica envolve diferentes sistemas, sendo eles: ecológico, biodinâmico, natural, regenerativo, biológico, agroecológicos, permacultura e outros que atendam os princípios da Lei n. ${ }^{\text {1 }}$ 10.831/2003 (Brasil, 2003).

A Lei n. ${ }^{\circ}$ 10.831/2003 foi um marco importante na legislação sobre a produção de orgânicos no país, pois definiu bases, conceitos e a finalidade de um sistema orgânico, que deve, entre outros: ofertar produtos saudáveis isentos de contaminantes intencionais; preservar a diversidade biológica; incrementar a atividade biológica do solo; promover o uso saudável dos recursos naturais; basear-se em recursos renováveis e em sistemas agrícolas organizados localmente (Brasil, 2003).

Nesse sentido, a conceituação de sistema orgânico no País é:

Art. 1 Considera-se sistema orgânico de produção agropecuária todo aquele em que se adotam técnicas específicas, mediante a otimização do uso dos recursos naturais e socioeconômicos disponíveis e o respeito à integridade cultural das comunidades rurais, tendo por objetivo a sustentabilidade econômica e ecológica, a maximização dos benefícios sociais, a minimização da dependência de energia não-renovável, empregando, sempre que possível, métodos culturais, biológicos e mecânicos, em contraposição ao uso de materiais sintéticos, a eliminação do uso de organismos geneticamente modificados e radiações ionizantes, em qualquer fase do processo de produção, processamento, armazenamento, distribuição e comercialização, e a proteção do meio ambiente (Brasil, 2003).

Com o objetivo de regular a Lei n. ${ }^{\circ}$ 10.831/2003, em 2007 foi publicado o Decreto n. ${ }^{\circ}$ 6.323/2007. O decreto estabelece três mecanismos de controle da produção de orgânicos no país: a) controle social na venda direta; b) sistema participativo de garantia, e; c) certificação por auditoria (Brasil, 2007). 
O controle social na venda direta sem certificação permite a comercialização direta para o consumidor, para isso os agricultores precisam estar vinculados a uma organização com controle social cadastrada no Ministério da Agricultura, Pecuária e Abastecimento (MAPA). Esse processo é mais flexível, menos custoso e promove circuitos curtos de comercialização de modo a facilitar a participação de pequenos produtores (Sambuichi et al., 2017).

O sistema participativo de garantia caracteriza-se pelo controle social e pela responsabilidade coletiva (Lima et al., 2020). Ele é composto pelos membros do próprio sistema, que podem ser produtores, comercializadores, consumidores entre outros previstos no Decreto n. ${ }^{\circ}$ 6.323/2007 - e, pela organização de avaliação da conformidade, credenciada no MAPA.

A certificação por auditoria pode ser feita por uma certificadora pública ou privada com credenciamento no MAPA, que irá avaliar orientar e certificar a produção. Assim, o produtor, após uma inspeção inicial, recebe visitas periódicas da certificadora que tem autonomia tanto para conceder quanto para retirar o certificado do produtor, em caso de descumprimento de alguma norma. Este processo pode ser mais custoso, e nem sempre se adéqua a todos os produtores, sendo mais comum em produtores maiores (Moraes; Oliveira, 2017).

Por fim, ressalta-se que o decreto instituiu o Sistema Brasileiro de Avaliação da Conformidade Orgânica, integrado por órgãos e entidades da administração pública federal e pelos organismos de avaliação da conformidade credenciados pelo MAPA. O sistema é responsável pela certificação por auditoria e pelo sistema participativo de garantia da qualidade orgânica, e sua identificação é feita por um selo utilizado em todo território nacional (Brasil, 2020).

\subsection{Cooperativismo Solidário e Circuitos Curtos de Comercialização}

A inserção da produção dos agricultores familiares no mercado é um grande desafio a ser enfrentado. Um dos problemas apontados é a logística. Os pequenos produtores tem grande dificuldade de comercializar seus produtos considerando os altos custos, impedindo um processo de escoamento mais eficiente. Nesse contexto muitas famílias de agricultores, unem-se a cooperativas rurais para manter-se no mercado, possibilitando aos agricultores oportunidades.

Segundo dados da Food and Agriculture Organization of the United Nations (FAO, 2015), no mundo, são mais de 500 milhões de propriedades familiares, que dependem e vivem da agricultura familiar, gerenciando a maioria das terras agrícolas do mundo e produzindo a maior parte dos alimentos. Esta atividade se mostra de grande importância social, na medida em que contribui significativamente para a erradicação da fome e pode atuar na conservação de recursos naturais (Graziano, 2013). Podendo atuar estrategicamente na garantia da segurança alimentar e nutricional as populações mundiais.

Segundo Ferreira (2004), o conceito de cooperação pode ser traduzido pela palavra do latim operare, ou seja, fazer algo, e a palavra colaboração por sua vez significam labore, ou seja, trabalho. O conjunto delas se traduz em trabalho coletivo, ou seja, realizado coletivamente (Fiorentini, 2004).

Neste contexto a atividade agrícola baseada no cooperativismo, se diferencia das demais por seu caráter solidário, organizacional, econômico, coletivo, colaborativo e que por vezes é baseado na sustentabilidade rural. A inserção do agricultor familiar neste segmento possibilita o acesso a novos mercados, a informações que levam a redução de custo, bem como o acesso a novas tecnologias, ou seja, possibilita a esse agricultor mais competitividade de mercado, uma vez que este está inserido numa economia de base capitalista.

Ferreira (1984) aponta para algumas para algumas vantagens dos agricultores ao se associar as cooperativas tais como: - economias de escala; - aumento da produção em decorrência da emulação que se estabelece; - possibilidade de realizar determinadas espécies de trabalho que requerem o concurso de elevado número de forças de trabalho simultaneamente.

$\mathrm{Na}$ coletividade proporcionada pelas cooperativas, o agricultor torna-se mais forte, buscando superar os riscos mercadológicos, custos com a produção, e na partilha de lucros, que deve ter caráter igualitário, baseado na coletividade (Konzen; Krause, 2002). 
O cooperativismo pode fortalecer o agricultor uma vez que ele the proporciona, capacitação, assistência técnica, intermediação financeira, estratégias organizacionais, bem como formação, contribuindo para a modernização do campo e diminuindo o êxodo rural, ou seja, as cooperativas têm poder de transformação do meio rural, uma vez que dá amparo ao agricultor, e por consequência garante o desenvolvimento rural.

E nesse contexto a Economia Solidária, se constrói a partir de um processo contínuo de luta contra a lógica do capitalismo. Centrado na organização dos trabalhadores na construção de projetos cooperativos, que podem dar-se desde unidades produtivas autogestionárias ou de pequenos produtores que se organizam para vender e comprar em conjunto, formando redes de comércio justo, através de incubadoras, gerando trabalho e renda de forma mais justa, solidária e sustentável.

Conforme Singer e Souza (2000), a economia solidária possibilita uma relação econômica distinta, na medida em que a posse dos meios de produção é coletiva. A gestão da empresa pode ocorrer de maneira mais democrática, ou direta a depender do número de cooperados, bem como a divisão dos lucros que ocorre de forma mais justa dependendo da decisão da assembleia, tanto quanto outras decisões de cunho administrativo, como cita Singer:

[...] O capital da empresa solidária é possuído pelos que nela trabalham e apenas por eles. Trabalho e capital estão fundidos porque todos os que trabalham são proprietários da empresa e não há proprietários que não trabalhem na empresa. E a propriedade da empresa é dividida por igual entre todos os trabalhadores, para que todos tenham o mesmo poder de decisão sobre ela (Singer, 2000, p. 83).

E neste contexto a economia solidária se apresenta como uma forma alternativa de economia. Logo, Dowbor (2006, p. 47) salienta que "não basta criar um ambiente favorável ao mercado, é preciso orientar a economia para o que dela a sociedade deseja". Assim a economia pode ser moldada com princípios e objetivos, com a melhoria da qualidade de vida das pessoas e com empreendimentos agregadores de objetivos sociais e ambientais.

No Brasil o setor agrícola é o que apresenta o cooperativismo melhor estruturado, e isso dá principalmente por três motivos: - o crescimento do potencial agrícola internacional; - a globalização; - o aumento crescente da competição internacional (Pinho, 2004). Assim o papel das cooperativas tem sido o de proporcionar aos agricultores estabilidade e segurança comercial, principalmente aos produtores de pequeno porte, viabilizando a concorrência num ambiente extremamente competitivo.

Nesta perspectiva o cooperativismo pode se dar como alternativa principalmente para os agricultores familiares, na medida em que estes podem gerenciar sistemas diferenciados de produção e comercialização, oferecendo preço justo, sem a interferência de atravessadores e se fortalecendo na coletividade.

Desta forma os circuitos curtos alimentares representam uma nova possibilidade de comercialização tanto para quem consome, quanto para quem produz, com condições mais justas de comercialização, evitando terceiros neste processo. Possibilitando a valorização da produção da agricultura familiar, com alimentos mais saudáveis, a partir da produção de alimentos orgânicos. Conforme apresenta Darolt: "Essa multiplicação dos circuitos curtos e de formas inovadoras de acolhida na propriedade pode potencializar a agricultura de base ecológica, aproximar agricultores e consumidores e reconectar o mundo rural e o urbano" (Darolt, et al., 2013, p. 10).

Segundo Darolt et al., (2013) o circuito curto (CC) alimentar pode ser compreendido como uma venda direta ao consumidor, ou ainda admitindo apenas um atravessador como explana:

Dois casos de CC podem ser distinguidos: a venda direta (quando o produtor entrega diretamente a mercadoria ao consumidor) e a venda indireta via um único intermediário (que pode ser outro produtor, uma cooperativa, uma associação, uma loja especializada, um restaurante ou até um pequeno mercado local) (Darolt et al., 2013, p. 09). 
Assim a entrega de cestas com alimentos orgânicos pode representar uma mudança importante para o consumidor bem como para o processo de organização da agricultura familiar a partir de cooperativas. Segundo Darolt et al., (2013), onde “(...) a maioria dos produtores de base ecológica com bons resultados de comercialização tem utilizado dois a três canais de venda (feiras do produtor, entrega de cestas a domicílio e mais recentemente, compras governamentais), embora exista uma gama de alternativas (...)" (Darolt et al., 2013, p. 09)

Esta nova concepção de comercializar pode representar uma troca formal ou informal entre produtores e sua rede de contatos possibilitando uma nova forma de consumir e produzir (Lamine, 2012).

Ao mesmo tempo em que estes circuitos fortalecem as relações entre consumidores e produtores numa relação mais direta, favorecendo princípios como, por exemplo: autonomia, solidariedade, segurança alimentar, justiça social, respeito à cultura e tradições locais (Darolt et al., 2013).

Num contexto global de economia capitalista, onde a concorrência acirrada, aliada a alta produtividade, cria um ambiental hostil ao produtor rural, às cooperativas podem amparar o pequeno produtor. $\mathrm{O}$ fortalecimento dessa cadeia produtiva pode se dar, exatamente por seu caráter familiar e colaborativo, onde as questões igualitárias se fazem mais presentes do que em outros setores ou cadeias produtivas.

\subsection{Análise Swot}

A Análise SWOT é uma ferramenta que vem dos termos em inglês strenghts, weaknesses, oportunities e threats, que, respectivamente, podem ser traduzidos como forças, fraquezas, oportunidades e ameaças (Diniz, 2014).

As oportunidades e ameaças compõem a análise do ambiente externo, ou macroambiente e as forças e fraquezas compõem a análise do ambiente interno, ou microambiente.

Sob a perspectiva interdisciplinar, Kummer (2007, p. 113) entende que a análise SWOT, também conhecida como matriz FOFA é uma ferramenta importante no planejamento participativo no meio rural, pois este permite "visualizar a situação futura onde se quer chegar, incluindo mudanças necessárias com a intenção de gerar impactos, ou seja, mudanças positivas e medíveis".

De acordo com Diniz (2014, p. 97), sob o prisma da administração, a Análise SWOT é um instrumento "utilizado nos planejamentos estratégicos das empresas porque força a organização a se confrontar com o ambiente (interno e externo)".

Nesse sentido, para verificar o desempenho do negócio, é importante que o empresário monitore as "forças macroambientais (econômicas, demográficas, tecnológicas, políticos-legais e socioculturais) e significativos agentes microambientais (clientes, concorrentes, distribuidores, fornecedores)" (Kotler; Keller, 2006, p. 50).

Conforme Nogueira (2014) a análise é feita por representação gráfica, com quadrantes para cada um dos pontos da matriz (forças, fraquezas, oportunidades e ameaças), de modo a facilitar a identificação e avaliação de cada ponto e permitir que haja uma comparação entre eles.

\subsection{Caracterização do Objeto de Estudo}

A Cooperativa Cores da Terra está situada no bairro São Cristóvão no município de Cascavel - PR. As primeiras articulações começaram no ano de 2016, com o objetivo de os produtores conquistarem novas oportunidades e adquirirem novos conhecimentos em relação às técnicas agrícolas, a fim de se distinguir das já existentes, além da melhoria de renda. Após esse período, a trajetória da cooperativa, pode ser observada através do Quadro 1 - Um histórico da Cooperativa Cores da Terra, como segue abaixo: 
Quadro 1 - Um histórico da Cooperativa Cores da Terra.

\begin{tabular}{|c|l|}
\hline $04 / 2017$ & $\begin{array}{l}\text { Formalização da Associação de Agricultores Orgânicos Cores da Terra e parceria com SEBRAE (Serviço Brasileiro de } \\
\text { Apoio às Micro e Pequenas Empresas) para consultoria de conversão das propriedades para produção orgânica; }\end{array}$ \\
\hline $05 / 2017$ & $\begin{array}{l}\text { Formalização da Associação de Agricultores Orgânicos Cores da Terra e parceria com SEBRAE (Serviço Brasileiro de } \\
\text { Apoio às Micro e Pequenas Empresas) para consultoria de conversão das propriedades para produção orgânica; }\end{array}$ \\
\hline $07 / 2017$ & Primeira participação no Curso de Agricultura Orgânica dos Produtores da Associação efetuado pelo SENAR; \\
\hline $03 / 2018$ & Firmado contrato de Incubação com a FUNDETEC; \\
\hline $10 / 2018$ & $\begin{array}{l}\text { Certificação dos Produtores da Associação Cores da Terra; } \\
\text { Assembleia de Fundação da Cooperativa de Produtores Orgânicos Cores da Terra; }\end{array}$ \\
\hline $03 / 2019$ & $\begin{array}{l}\text { Comercialização das CESTAS, venda Direta ao consumidor; } \\
\text { Locação do barracão, endereço sede da Cooperativa; }\end{array}$ \\
\hline $05 / 2019$ & $\begin{array}{l}\text { Formalização Oficial da Cooperativa - emissão CNPJ; } \\
\text { Encerramento processo de incubação a distância na FUNDETEC; }\end{array}$ \\
\hline $10 / 2019$ & $\begin{array}{l}\text { Certificação Orgânica da Marca CORES DA TERRA; } \\
\text { Primeira entrega: início das vendas a varejo dos produtos embalados. }\end{array}$ \\
\hline $2020 / 2021$ & $\begin{array}{l}\text { Suspensão das cestas; } \\
\text { Parceria com a Associação dos Produtores Orgânicos de Palmas Paraná (APROPAL); }\end{array}$ \\
\hline
\end{tabular}

Fonte: Elaborado pelos autores (2020).

O processo de legalização da Associação de Agricultores Orgânicos Cores da Terra, teve a participação de 10 produtores locais e, assim, a preparação das áreas rurais para a produção orgânica foi iniciada. A ideia de começar os trabalhos organizados em associação teve como propósito a criação da marca e a busca por mercados.

Ao longo das entrevistas (2020 e 2021) a cooperativa contava com cerca de 20 produtores certificados pelo $2^{\circ}$ ano consecutivo pela Certificação Orgânicos Brasil. A cooperativa contava com o mínimo de sócios necessários para a criação da cooperativa, ou seja, 13 associados ativos, com 5 efetivamente produzindo. Em 2020, haviam 20 produtores esperando para receber a certificação. Eles produzem alimentos orgânicos, como hortaliças e frutas, conforme a Lei da Produção Orgânica vigente, Lei n. ${ }^{\circ}$ 10.831/2003 (Brasil, 2003), contribuindo assim, para uma alimentação saudável tendo em vista a sustentabilidade.

Outro elemento importante a ser considerado neste processo é a mão de obra. Muitos produtores utilizavam mão de obra somente familiar, já outros contavam com funcionários para ajudarem nas tarefas diárias. Em relação ao perfil dos produtores associados à cooperativa, todos eram agricultores familiares e estavam vinculados ao programa do Governo Federal (PRONAF), por meio de Declaração de Aptidão ao PRONAF (DAP), esse programa proporciona apoio financeiro para os estabelecimentos rurais.

A cooperativa relatou que a parceria com o Serviço Brasileiro de Apoio as Micro e Pequenas Empresas (SEBRAE) estava ativa e, além disso, os cooperados faziam parte de um programa financiado pela Itaipu, que disponibiliza técnicos para assistência rural. Essas assistências técnicas contribuíram para a evolução da produção desde o início de sua criação. Segundo relatado na entrevista os produtores melhoraram a sua experiência com os orgânicos, tendo em vista que muitos tinham dificuldades em relação a quanto produzir e como produzir na busca por formas mais sustentáveis, muitos deles alcançaram melhorias nestes âmbitos e ainda conseguiram diminuir a quantidade de pragas, quesito importante quando trata-se da produção de orgânicos. 
A questão da sustentabilidade e qualidade de vida das pessoas são fatores bases para o seu objetivo, conforme o site da Cooperativa Cores da Terra (2020):

Temos como objetivo a prática dos conceitos basilares da sustentabilidade, respeito ao meio ambiente; valorizando a produção agrícola familiar e a melhoria da qualidade de vida destes e dos consumidores. Por isso, todos alimentos que oferecemos são de excelente qualidade nutricional, livre de agrotóxicos e fertilizantes químicos. Somos reconhecidos pelo incentivo a pequenos produtores que trabalham de maneira sustentável, sem o uso qualquer tipo de agrotóxicos e fertilizantes químicos (CORES DA TERRA, 2020).

Em relação à abrangência de municípios da cooperativa, caracteriza-se como regional, contemplando sócios de Cascavel, Toledo, Três Barras do Paraná e Quedas do Iguaçu. Todos seguiam o mesmo padrão de qualidade na produção dos produtos e cuidados com o meio ambiente.

Segundo a diretora da cooperativa, o produtor que tem a pretensão de se tornar um cooperado precisaria investir uma cota capital no valor de $\mathrm{R} \$ 1.000,00$. Tal cota poderia ser paga da seguinte forma: $50 \%$ do valor pago em dinheiro e $50 \%$ do valor pago em produção.

Considerando a rotina da vida moderna onde as pessoas parecem ter cada vez menos tempo, e consequentemente deixam de ter uma vida saudável, pela rotina e hábitos alimentares errôneos, a Cores da Terra elaborou um serviço de entrega semanal com alimentos frescos, possibilitando uma alimentação mais saudável e com maior teor nutritivo às visando este público. Inicialmente pensou-se em vender no varejo, no entanto em 2019, passaram a trabalhar com as cestas de entrega a domicilio.

Neste modelo, por meio de assinaturas de planos mensais, o consumidor efetuava o pedido via aplicativo WhattsApp para receber em sua residência uma cesta de produtos orgânicos selecionados de acordo com a estação do ano ou, ainda, agendava a retirada em um dos 11 pontos de entrega disponíveis na cidade de Cascavel - PR ou em 02 pontos de entrega na cidade de Toledo - PR. A cooperativa já chegou formar 80 cestas semanais.

Em 2020, havia três opções de assinaturas de planos mensais para as cestas de produtos, sendo elas: Individual, contemplando cinco itens, no valor de R \$90,00; o plano Casal possuía sete itens, no valor de R \$118,00 e o plano Família contava com a seleção de dez itens pelo valor de $\mathrm{R} \$ 164,00$, eram quatros entregas no mês.

A cooperativa também entregava produtos embalados no varejo, nos seguintes locais: Frutaria Maçã Verde, rede de supermercados Beal e Irani de Cascavel - PR e redes de supermercados Primato de Toledo - PR. Ambas as formas de vendas possuíam entrega terceirizada. Outra forma de comercialização acontecia por meio da feira local que acontece aos sábados de manhã, os produtos ofertados são orgânicos e não orgânicos, ou seja, a feira era para os agricultores rurais que tiverem interesse em vender seus produtos. Dois dos produtores também participavam da feira do pequeno produtor do município, entretanto, no final do ano de 2021 esses canais de comercialização foram suspensos, principalmente, por conta da pouca produção dos produtores que priorizaram outros mercados, problemas financeiros e questões climáticas.

Assim, a cooperativa tinha um papel estratégico ao proporcionar um sistema alternativo de comercialização em circuito curto. Segundo Darolt, Brandemburg e Lamine (2013, p. 12) esse modelo aproxima os agricultores dos consumidores, reconecta o mundo rural com o urbano e contribui "para a adoção de hábitos de consumo mais saudáveis e um melhor conhecimento das dificuldades na produção agrícola".

Nesse sentido, os autores entendem que, para que os princípios de um comércio justo, solidário e sustentável sejam mantidos, são necessárias "ferramentas de monitoramento e análise que permitam avaliar a conformidade dos produtos ecológicos comercializados em circuitos curtos" (Darolt; Brandemburg; Lamine, 2013, p.13).

Nesta seção serão descritos os resultados da pesquisa, descrevendo as informações do microambiente e do macroambiente, com a análise do ambiente interno e externo em relação aos atributos identificados no estudo da cooperativa. 
Ao longo da pesquisa foram identificados nove pontos fortes que contribuem para a expansão e fortalecimento da Cooperativa, no entanto, oito pontos foram caracterizados como fracos, os quais seria um erro grave negligenciá-los. Em relação aos fatores que geram oportunidades, foram identificados vários pontos que podem ser utilizados para vantagem competitiva e consolidação neste mercado, por fim, temos os pontos de ameaças, eles podem trazer prejuízos para a cooperativa caso não tenham a atenção necessária. O Quadro 2 - Análise do Microambiente/Macroambiente - Matriz SWOT, evidencia esta analise, como segue abaixo:

Quadro 2 - Análise do Microambiente/Macroambiente - Matriz SWOT.

\begin{tabular}{|c|c|}
\hline \multicolumn{2}{|c|}{ AMBIENTE INTERNO - MICROAMBIENTE } \\
\hline Forças & Fraquezas \\
\hline $\begin{array}{l}\text { - Mercado de orgânicos } \\
\text { - Capacidade de aumentar a variedade de produtos } \\
\text { - Certificação } \\
\text { - Absorção da produção } \\
\text { - Qualidade dos produtos } \\
\text { - Parcerias } \\
\text { - Mudança no estilo de vida e consciência dos produtores } \\
\text { - Pontos de entrega/entrega à domicílio } \\
\text { - Cestas de produtos }\end{array}$ & $\begin{array}{l}\text { - Apoio financeiro } \\
\text { - Investimentos } \\
\text { - Assessoria técnica aos produtores } \\
\text { - Número reduzido de funcionários } \\
\text { - Logística } \\
\text { - Marketing } \\
\text { - Instalações } \\
\text { - Gestão }\end{array}$ \\
\hline \multicolumn{2}{|l|}{ AMBIENTE EXTERNO - MACROAMBIENTE } \\
\hline Oportunidades & Ameaças \\
\hline $\begin{array}{l}\text { - Projeto de implantação de cereais, estudos de viabilidade } \\
\text { em parceria com o SEBRAE } \\
\text { - Fornecer produtos para programas institucionais } \\
\text { - Aumento da conscientização socioambiental } \\
\text { - Diretrizes para alimentação escolar } \\
\text { - Preocupação com a segurança alimentar e nutricional } \\
\text { (mudanças de comportamento do consumidor) } \\
\text { - Rastreabilidade do produto } \\
\text { - Pandemia }\end{array}$ & $\begin{array}{l}\text { - Falta de incentivos para a produção familiar (Pol. Públicas) } \\
\text { - Sazonalidade dos produtos } \\
\text { - Controle de pragas / doenças } \\
\text { - Intempéries climáticas }\end{array}$ \\
\hline
\end{tabular}

Fonte: Elaborado pelos autores (2020).

A seguir será apresentada a análise dos ambientes interno e externo, contemplando cada ponto identificado nas entrevistas.

\subsection{Análise do Microambiente}

A análise do microambiente contempla a análise dos fatores internos da cooperativa estudada. Ela consiste na identificação dos pontos fortes e fracos, que geram oportunidades ou colocam em risco o desenvolvimento e a competitividade do negócio. Assim foi realizada uma análise dos pontos fortes da Cooperativa:

Foram identificados como potencialidades os seguintes atributos internos da Cooperativa Cores da Terra:

a) Mercado de orgânicos: É um ponto forte, devido às mudanças de hábitos dos consumidores, os quais estão em busca de uma alimentação mais saudável, evitando o consumo de alimentos que possam causar algum malefício à saúde, também está relacionado à conscientização sócio ecológica, com preocupação com o meio ambiente e às políticas públicas que 
incentivam este mercado, a exemplo do PNAE (Programa Nacional de Alimentação Escolar) que estabelece a compra de 30\% destes produtos. Para Sachs (2004), produzir de forma sustentável está associado ao bom uso da natureza, para ele precisamos observar as relações humanas com a biosfera e não somente os atributos sociais e econômicos;

b) Capacidade de aumentar a variedade de produtos: Os produtores da cooperativa possuíam capacidade de oferecer produtos novos aos clientes. Durante o período das entrevistas estava sendo realizado um estudo de viabilidade para a produção de cereais;

c) Certificação: A certificação é um dos principais pontos fortes da Cores da Terra, ela contribui para que o consumidor identifique os produtos e as empresas de qualidade, além de agregar valor ao produto e gerar mais renda para o produtor;

d) Absorção da produção: A cooperativa tinha capacidade de absorver toda a produção dos produtores, esse fator é muito positivo para os cooperados, pois eles têm a garantia da compra dos produtos;

e) Qualidade dos produtos: É considerado um ponto forte. A cooperativa produzia alimentos sustentáveis, orgânicos, ou seja, alimentos saudáveis e seguros, produzidos sem o uso de agrotóxicos, conforme as exigências da Lei da Produção Orgânica vigente - Lei n. ${ }^{\circ}$ 10.831/2003 (Brasil, 2003).

f) Parcerias: A cooperativa contava com a parceria do SEBRAE, durante o período das entrevistas estava sendo realizado um estudo de viabilidade para a produção de cereais como forma de diversificar os produtos ofertados. Os associados também contavam com o apoio de um programa financiado pela Itaipu, que disponibiliza técnicos para assistência rural. Em 2021 uma nova parceria foi firmada com a Associação dos Produtores Orgânicos de Palmas Paraná (APROPAL) do município de Palmas - PR, com o objetivo de repassarem a gestão da cooperativa a eles e também, conseguirem uma maior quantidade de produtos e assim, participarem da chamada pública para entrega para o PAA do município de Cascavel - PR neste ano. Além disso, de acordo com a gestora administrativa a sede da cooperativa será em Palmas, na associação APROPAL;

g) Mudanças no estilo de vida e a consciência dos produtores: Houve mudanças em relação à qualidade de vida, e na alimentação dos produtores. Além disso, alguns produtores perderem o medo de buscarem a produção mais sustentável, pois perceberam na Cooperativa um incentivo. Sentiram-se motivados pela oportunidade de melhoria da renda, pois sabiam que esse era um grande nicho de mercado, ao mesmo tempo em que acreditavam na sustentabilidade, ou seja, produzir alimentos com um meio ambiente sadio, proporcionando mais saúde;

h) Pontos de entrega/entrega a domicílio: A correria do dia a dia faz com que cada vez menos conseguimos fazer uma alimentação saudável e com a pandemia a insegurança em se alimentar fora de casa. Nesse contexto, a Cores da Terra possuía 11 pontos de entregas dos produtos, distribuídos em bairros da cidade de Cascavel - PR e 02 pontos de entrega em Toledo PR. Além disso, proporcionava comodidade para os consumidores com a entrega de produtos na residência do cliente semanalmente;

i) Cestas de produtos: Até o final do ano de 2020 a Cooperativa ofertava aos seus consumidores cestas de alimentos orgânicos. As cestas eram formadas por diversos produtos selecionados de acordo com a estação e entregues semanalmente. Por meio de assinaturas de planos mensais, o consumidor tinha a opção de entrega a domicílio ou agendamento para a retirada em um dos pontos de entrega disponíveis.

Pode-se afirmar com esta análise a existência de diversos pontos fortes na Cooperativa Cores da Terra, os quais podem ser utilizados como vantagem competitiva. Alguns possuem maior probabilidade de sucesso, como abertura de novos mercados para os produtos orgânicos, a certificação, a qualidade do produto e a possibilidade de produção de novos produtos, como os cereais. 


\subsubsection{Análise dos pontos fracos da cooperativa}

Alguns pontos fracos foram identificados na Cooperativa Cores da Terra, eles representam as deficiências que necessitam de atenção. São eles:

a) Apoio financeiro: Grande parte dos agricultores não disponibilizava de recursos próprios para investirem na sua produção e como a cooperativa é relativamente nova, os recursos ainda eram escassos. Esse fator foi o que mais comprometeu a entrega das cestas no final do ano de 2020, de acordo com a gestora administrativa da cooperativa Silvana, sem recursos financeiros a Cores da Terra deixou de pagar alguns agricultores associados, impactando diretamente nos produtos que compunham as cestas, contribuindo para a suspensão da entrega das cestas;

b) Investimentos: Esse ponto está diretamente ligado ao apoio financeiro, os produtores e nem a cooperativa dispõem de recursos financeiros para investirem. E quando faziam investimentos, por vezes, eles eram baixos em relação às suas necessidades, o dificultava a expansão da produção, a diversificação de produtos, bem como o aperfeiçoamento de técnicas de produção, armazenamento e distribuição, entre outros;

c) Assessoria técnica aos produtores: Mesmo com as parcerias para esse quesito, havia uma carência deste tipo de serviço, o que também dificultava a expansão da produção, por exemplo;

d) Número reduzido de funcionários: A Cores da Terra trabalhava com um número reduzido de funcionários. Uma pessoa agregava várias funções, o que dificulta o gerenciamento. O Moacir, diretor da Cooperativa, não estava atuando durante o período da pesquisa. A Silvana é a diretora e secretária, a qual é responsável pelo dia a dia das operações. Em 2020 contrataram uma estagiária para ajudar na documentação;

e) Logística: A logística foi considerada um ponto fraco, pois as entregas dos produtos eram terceirizadas, tornando o processo de distribuição mais oneroso;

f) Marketing: Por conta do número reduzido de funcionários e pouco apoio financeiro, uma vez que, a Cores da Terra não possuía assessoria paga, a Cooperativa relatou dificuldades na área de marketing, elemento importante para captação de novos clientes. Houve uma retomada nesta atividade, foi criada uma conta no Instagram, a qual seria gerida pela nova secretaria contratada pela cooperativa. Parcerias com alguns influencers digitais também foram firmadas durante o período das entrevistas. Além disso, a cooperativa enviava cestas de produtos como cortesia a algumas pessoas que, em contrapartida, faziam as divulgações, tal feito trouxe resultados significativos. Foi contratada uma empresa para criar o site e havia um estudo visando à possibilidade de investir em marketing para divulgação da marca e dos produtos que são entregues aos supermercados;

g) Instalações: As instalações não atendiam expansão. A infraestrutura era mínima para o trabalho e não atenderia as necessidades futuras, porém, por questões financeiras, durante as entrevistas, a Cooperativa não tinha como ampliar ou mudar de espaço. Em 2020, foi relatado que eles estavam analisando a possibilidade de melhorar o espaço com apoio da iniciativa pública. Porém, em 2021, a instalação não continuou ativa devido aos problemas já citados e, com a parceira com a associação APROPAL, ficou acordado que esta sediará a Cooperativa;

h) Gestão: Na metade do ano de 2020, os custos operacionais e administrativos eram muito maiores do que o faturamento, e ao mesmo tempo não havia um capital de giro para manter os custos, assim, a Cooperativa não conseguiu atingir um grau de equilíbrio neste sentido, além disso, com a falta de pagamento dos produtores deixaram de entregar para a cooperativa, o que acarretou na suspensão das cestas por tempo indeterminado.

Como pode ser observado, a Cores da Terra apresentou alguns pontos fracos que mereceram atenção e devem ser analisados pela gestão. Pontos estes que podem ter comprometido o crescimento da cooperativa, como por exemplo, o apoio financeiro, o qual implicou em outros pontos a necessitam de uma nova estratégia. 
Na sequência está descrita a análise do ambiente externo à cooperativa, ela está dividida em pontos percebidos como oportunidades e pontos identificados como ameaças, os quais podem impedir crescimento da cooperativa estudada.

\subsection{Análise do Microambiente}

Essa análise consiste na verificação dos pontos dos recursos externos da empresa. Neste sentido, há atributos que geram oportunidades e outros que colocam em risco o desenvolvimento e a competitividade da Cores da Terra. Assim realizouse uma análise das oportunidades da cooperativa:

a) Projeto de implantação de cereais, estudos de viabilidade em parceria com o SEBRAE: Parcerias com instituições são benéficas e podem favorecem o desenvolvimento das propriedades rurais, pois as mesmas buscam atender diretamente a necessidade dos cooperados, motivando e fortalecendo as cooperativas. $\mathrm{O}$ suporte com pesquisas científicas é fundamental para diversos fatores, dentre eles a ampliação da diversidade de produtos ofertados. Durante as entrevistas, a Cores da Terra participava de um estudo de viabilidade realizado pelo SEBRAE, para possibilitar maior variedade de produtos ofertados e consequente, novos mercados e mais renda para o produtor. A parceria com a associação APROPAL também foi observada como uma oportunidade no ano de 2021, ela possibilitou a participação da chamada pública do PAA do município de Cascavel $-\mathrm{PR}$;

b) Fornecer produtos para programas institucionais: Ao longo das entrevistas, a Cooperativa demonstrou interesse em fornecer produtos para programas institucionais governamentais, como por exemplo o PAA e o PNAE, sendo que o último adquire produtos orgânicos para preparar a alimentação escolar. Essa oportunidade foi aproveitada pela Cores da Terra no início de 2021, com a parceria firmada com a associação APROPAL do município de Palmas - PR, com o objetivo de repassarem a gestão da cooperativa a eles e também, para participarem da chamada pública para entrega para o PAA do município de Cascavel - PR no ano de 2021;

c) Aumento da conscientização socioambiental: há um nicho de mercado cujos consumidores são preocupados com a produção de alimentos socialmente corretos e baseados na sustentabilidade ambiental. A cooperativa percebeu que essa é uma oportunidade forte para conquistar cada vez mais clientes para os seus produtos e segue rigorosamente a legislação da produção orgânica em vigor, Lei n. ${ }^{\circ}$ 10.831/2003 (BRASIL, 2013). Foi realizada uma pesquisa com os consumidores para saber a opinião deles sobre os produtos, uma pessoa de fora da cooperativa entrou em contato com as pessoas que recebem as cestas semanalmente e resultado foi positivo;

d) Diretrizes para alimentação escolar: Os governos de todas as esferas têm apresentado diretrizes para o atendimento da alimentação escolar com a elaboração de leis. Uma delas é a Lei n. ${ }^{\circ}$ 11.947/2009 (BRASIL, 2009), a qual estabelece que $30 \%$ dos produtos comprados para alimentação escolar devem ser provenientes da agricultura familiar;

e) Preocupação com a segurança alimentar e nutricional (mudanças de comportamento do consumidor): Cada vez mais o consumidor tem se preocupado com sua saúde e qualidade de vida, buscando produtos com qualidade, nutritivos e produzidos sustentavelmente. $\mathrm{O}$ aumento desta preocupação favorece a produção consciente, agregando valor ao alimento produzido. Para Boff (1999), é preciso ter cuidado com a natureza e com o corpo humano, para ele, sem o cuidado deixamos de ser humanos, ou seja, precisamos de cuidados desde o nascimento até a morte, caso contrário definhamos, perdemos o sentido e morremos. Assim, é preciso proteger a saúde, pois a doença causa danos a nossa existência. Neste sentido, o consumo de alimentos saudáveis e seguros promovem a saúde humana;

f) Rastreabilidade do produto: O histórico de todas as etapas de produção, fabricação e distribuição dos produtos é obrigatório para conseguir algumas certificações nacionais e internacionais. $\mathrm{O}$ consumidor busca saber a procedência de seu alimento, é um diferencial competitivo que abre espaço para novos mercados.

Pandemia: Até o final do ano de 2020, a pandemia estava afetando positivamente as atividades da cooperativa, apesar 
da redução da venda de produtos embalados, aumentou o número de cestas entregues, por conta do isolamento social, parte da população passava mais tempo em casa e preparavam suas refeições diariamente, cenário este que favoreceu a venda das cestas dos produtos. Em relação à venda dos produtos embalados, a situação não é tão ruim, mas os mercados descontam no valor a ser pago, o percentual relacionado aos produtos que eles não vendem.

\section{Considerações Finais}

Conforme detalhamento da análise do macroambiente constatou-se que existem oportunidades a serem exploradas pela Cooperativa Cores da Terra. Grande parte destas oportunidades está associada ao aumento da conscientização socioambiental e mudanças de comportamento do consumidor, em relação ao consumo de produtos saudáveis e produzidos de maneira sustentável. A possibilidade da venda para programas institucionais e parcerias para pesquisas científicas são atributos que favorecem a competitividade no mercado, são pontos positivos que viabilizam a expansão da produção e a diversificação dos produtos. Nesta perspectiva foi realizada uma análise considerando os pontos de ameaças as atividades da cooperativa. Análise das ameaças da Cooperativa.

A análise do ambiente externo refere-se à identificação das ameaças, nesta pesquisa encontramos cinco atributos que podem impedir o desenvolvimento da cooperativa:

a) Falta de incentivos para a produção familiar (Políticas Públicas): O governo Federal diminuiu os recursos para algumas áreas, houve cortes no orçamento em relação há programas/políticas públicas que incentivam e fortalecem a agricultura familiar, como por exemplo: o PAA;

b) Sazonalidade dos produtos: A diversidade de produtos comercializados ocorre de acordo com a estação do ano. É preciso ter organização para que os clientes fiquem satisfeitos e não gere a redução da capacidade de produção, o que acarretaria na diminuição da renda dos produtores e da cooperativa;

c) Controle de pragas/doenças: $\mathrm{O}$ uso de agrotóxicos ou qualquer outro produto que agrida o meio ambiente e cause malefícios à saúde das pessoas, não podem ser utilizados neste tipo de produção, não condiz com as exigências da Lei da Produção Orgânica, assim, a busca por técnicas naturais para conter pragas e doenças é corriqueiro, podendo gerar prejuízos caso o problema não seja resolvido em tempo hábil;

d) Intempéries climáticas: No mundo rural o clima é um fator de preocupação, atualmente temos percebido mudanças negativas no nosso clima, elas são altamente prejudiciais à produção de alimentos. A falta ou excesso de chuva, por exemplo, pode comprometer a produção. A região em que situam os cooperados passou por um período de seca (2020/21), que isso afetou a produção e consequentemente, causou um impacto na composição das cestas de alimentos, sendo mais um fator que contribuiu para a suspensão das assinaturas.

Verifica-se que existem algumas ameaças encontradas pela Cores da Terra, porém, em menor número do que as oportunidades. Percebe-se que algumas das ameaças estão ligadas a fatores sobre os quais é difícil ter o controle, como o controle de pragas e doenças e fatores climáticos, no entanto, é possível elaborar estratégias para mitigar esses riscos para não comprometer a produção e garantir a satisfação dos clientes.

$\mathrm{O}$ uso de ferramentas de gestão pode auxiliar o processo administrativo, que é fundamental para a geração de renda e para a promoção da sustentabilidade, através de experiências alternativas de produção e comercialização de alimentos. Neste sentido, a análise SWOT permite que as empresas percebam quais são os pontos de melhorias e os pontos que podem gerar força e oportunidades para expansão futura de suas atividades, assim como as ameaças a que estão vulneráveis. Com a análise do ambiente interno e externo é possível verificar se as ações tomadas estão acarretando resultados positivos e ainda, ajuda no entendimento de quais serão as próximas medidas para melhorias dos serviços prestados, por exemplo. 
A referida cooperativa apresentou mais oportunidades e pontos fortes, se comparado aos pontos negativos, isso significa que a cooperativa está no caminho certo, com possibilidade de expansão por meio de novos negócios, novos produtos e novas parcerias. A análise identificou vários fatores positivos, dentre eles pode-se destacar a certificação, o aumento da conscientização socioambiental e mudanças de comportamento do consumidor, com a preocupação com a segurança alimentar e nutricional, os quais podem indicar prosperidade e sucesso.

Destacamos que a pandemia do Coronavírus (Sars-Covid19), em um primeiro momento, se tornou uma oportunidade de comercialização de produtos agroecológicos, em especial das cestas ofertadas pela Cooperativa. A transformação nos hábitos dos consumidores durante este período, em especial na busca por uma alimentação mais saudável e segura, e o maior tempo para o preparo de refeições, foram fatores que influenciaram no aumento da procura pelos alimentos ofertados pela Cooperativa.

No entanto, alguns pontos fracos e ameaças suscitaram na suspensão das cestas no final no ano de 2020, em especial, destaca-se a falta apoio financeiro e dificuldade de gestão. Tais pontos refletem negativamente em diversos outros, como logística e número de funcionários.

Por fim, destaca-se que a parceria com a APROPAL trouxe novas oportunidades à Cooperativa Cores da Terra, como a participação no PAA e nova gestão. Além disso, tal parceria pode apresentar novas potencialidades a Cooperativa, as quais, inclusive, poderiam ser objeto de futuros estudos.

Conclui-se com a pesquisa, que esta experiência de economia solidária e agroecológica formata novos desenhos de mercado agroecológico, com consciência socioambiental, com uma relação ética entre produtores e consumidores, com a construção de um mercado justo e na segurança alimentar e nutricional.

\section{Referências}

Abramovay, R. (2007). Paradigmas do Capitalismo Agrário em questão. São Paulo. Anpocs, Edusp, 2007. "Uma nova extensão para a agricultura familiar". In: Seminário Nacional De Assistência Técnica e Extensão Rural. Brasília, DF, Anais,1997, p. 29.(Texto para discussão).

Altieri, M. (2008). Agricultura familiar camponesa como patrimônio ecológico planetário. In: Altieri, M. Agroecologia: bases científicas para uma agricultura sustentável. São Paulo: Expressão Popular; Rio de Janeiro: AS-PTA, 2012 [2008]. p. 363-378.

Altieri, M. (2004). Agroecologia: a dinâmica produtiva da agricultura sustentável. (2a . ed.). Editora da UFRGS.

Boff, L. (1999). Saber cuidar: ética do humano, compaixão pela terra. Petrópolis (RJ): Vozes.

Brasil. (2007). Decreto $\mathrm{n}^{\mathrm{o}}$ 6.323, de 27 de dezembro de 2007. Regulamenta a Lei no 10.831, de 23 de dezembro de 2003, que dispõe sobre a agricultura orgânica, e dá outras providências. Brasília, DF: Presidência da República.

Brasil. (2003). Lei $n^{\circ} 10.831$, de 23 de dezembro de 2003. Dispõe sobre a agricultura orgânica e dá outras providências. Brasília, DF: Presidência da República.

Brasil. (2006). Ministério do Desenvolvimento Agrário (MAPA). Agricultura familiar no Brasil e o censo agropecuário.

Brasil. (2006). Senado Federal. Lei no 11.326, de 24 de julho de 2006. Estabelece as diretrizes para a formulação da Política Nacional da Agricultura Familiar e Empreendimentos Familiares Rurais.

Brasil. (2020). Ministério da Agricultura, Pecuária e Abastecimento (MAPA).

Campos, S. P. L. (2020). Entrevista concedida a Dariny Schoder Bonato. Cascavel, 16 mar. 2020.

Campos, S. P. L. (2020). Entrevista concedida a Dariny Schoder Bonato. Cascavel, 29 mar. 2020.

Campos, S. P. L. (2021). Entrevista concedida a Elaine Zanini. Cascavel, 12 maio. 2021.

Caporal, F. R. (2009). Extensão Rural e Agroecologia: temas sobre um novo desenvolvimento rural, necessário e possível. Brasília.

Caporal, F. R. \& Costabeber, J. A. (2004). Agroecologia: alguns conceitos e princípios. Brasília: MDA/SAF/DATER-IICA.

Carneiro, F. F. (2015). Dossiê ABRASCO: um alerta sobre os impactos dos agrotóxicos na saúde. Rio de Janeiro: EPSJV; São Paulo: Expressão Popular.

Darolt, M. R. \& Lamine, C. \& Brandenburg, A. A diversidade dos circuitos curtos de alimentos ecológicos: Ensinamentos do caso brasileiro e francês. Revista Agriculturas, 10(2), 8-13, 2013. 
Diniz, A. L. M. (2014). Estratégias de Gestão e Organização Empresarial. São Paulo: Pearson Education do Brasil.

Dowbor, L. (2006). Democracia econômica: um passeio pelas teorias. São Paulo.

Esquerdo, S. V. F. \& Bergamasco, S. M. P. P. (2015). Políticas públicas para a agricultura familiar brasileira: um estudo sobre o PRONAF nos municípios do circuito das frutas - SP. Revista Extensão Rural, Santa Maria, RS, 22(1), jan./mar. 2015.

FAO (2015) - Organização das Nações Unidas para Alimentação e Agricultura. Social protection and agriculture: breaking the cycle of rural poverty.

Ferreira, A. B. H. (2004). Novo dicionário Aurélio da língua portuguesa. Ed. Positivo.

Ferreira, C. G. (1984). Processo de trabalho, tecnologia e qualificação - notas para discussão. Belo Horizonte: CEDEPLAR/UFMG, 1984. (Texto para discussão, 16).

Fiorentini, D. (2004). Pesquisar práticas colaborativas ou pesquisar colaborativamente? In: Borba, M. C.; Araújo, J. L. (Org.). Comunidades interativas de aprendizagem. Belo Horizonte: Autêntica, 2004. p. 47-76.

Gil, A. C. (2010). Como elaborar projetos de pesquisa. (5 . ed.). Atlas.

Graziano, J. S. (2019). Não há nada mais avançado do que o potencial da agricultura familiar. 2013. Brasília; Rio de Janeiro: IPEA.

Guanziroli, C. E. \& Cardim, S. E. C. S. (2000). Novo retrato da agricultura familiar: o Brasil redescoberto. Brasília: Ministério do Desenvolvimento Agrário, INCRA, Instituto Nacional de Colonização e Reforma Agrária.

Konzen, G. O. \& Krause, E. L. (2002). Cooperativismo: a empresa, sua contabilidade, sua auditoria. Unisinos - série cooperativismo e desenvolvimento rural e urbano. Cadernos Cedope, 13(22).

Kotler, P. \& Keller, K. L. (2006). Administração de marketing. Tradução Mônica Rosenberg et al. (12 ${ }^{\mathrm{a}}$. ed.).: Person Prentice Hall.

Kummer, L. (2007). Metodologia participativa no meio rural: uma visão interdisciplinar. Conceitos, ferramentas e vivências. Salvador: GTZ.

Lamarche, H. (1983). L'agriculture familiale: une réalité polymorphe. Paris: L'Harmattan.

Lamine, C. (2012). Changer de système: une analyse des transitions vers l'agriculture biologique à l'echelle des systèmes agrialimentaires territoriaux. Terrains et Travaux, v. 20, p. 139-156.

Lima, S. K. (2020). Produção e consumo de produtos orgânicos no mundo e no Brasil. Brasília: Rio de Janeiro: Ipea.

Marconi, M. A. \& Lakatos, E. M. (2004). Metodologia Científica. (4ª. ed.). Atlas.

Martins, G. A. \& Theóphilo, C. R. (2009). Metodologia da investigação científica para ciências sociais aplicadas. (2ª . ed.). Atlas.

Moraes, M. D. \& Oliveira, N. A. M. (2017). Produção Orgânica e agricultura familiar: obstáculos e oportunidades. Revista Desenvolvimento Socioeconômico em Debate - RDSD. 2017. 3(1), 19-37.

Moura, I. F. (2017). Antecedentes e aspectos fundamentais da agroecologia e da produção orgânica na agenda das políticas públicas no Brasil. In: Sambuichi, R.H. R. A política nacional de agroecologia e produção orgânica no Brasil: uma trajetória de luta pelo desenvolvimento rural sustentável. Brasília: IPEA, 2017. p. 25-51.

Nogueira, C. S. (2014). Planejamento estratégico. Pearson Education do Brasil.

ONU (2019). Organização das Nações Unidas. Agricultores familiares são essenciais para subsistência global.

Paula, M. M. \& Kamimura, Q. P. \& Silva, J. L. G. (2014). Mercados institucionais na agricultura familiar: dificuldades e desafios. Revista de Política Agrícola, n. 1, p. 33-43.

Pereira, E. L. \& Nascimento, J. S. (2014). Efeitos do Pronaf sobre a produção agrícola familiar dos municípios tocantinenses. Revista de Economia e Sociologia Rural, Piracicaba, SP, 52(1), 139-156, jan./mar.

Pinho, D. B. (2004). O cooperativismo de crédito no Brasil. São Paulo: Confebrás.

Plein, C. \& Filippi, E. E. (2011). Capitalismo, agricultura familiar e mercados. Revista Desenvolvimento Regional, 16(3), 98-121.

Rosa, C. A. R. (2013). Como elaborar um plano de negócios. Brasília: SEBRAE.

Sachs, I. (2004). Desenvolvimento sustentável - desafio do século XXI. Ambiente \& Sociedade, 7(2), jul./dez.

Sambuichi, R. H. R. (2017). A política nacional de agroecologia e produção orgânica no Brasil: uma trajetória de luta pelo desenvolvimento rural sustentável. Brasília: IPEA.

Singer, P. (2000). Economia Solidária: um modo de produção e distribuição. In: Singer, P. \& Souza, A. R. (org.). A Economia Solidária no Brasil: A autogestão como resposta ao desemprego. São Paulo: Editora Contexto.

Yin, R. (2010). Estudo de caso: planejamento e métodos. (4a. ed.). Bookman.

Zonin, W. J. \& Brandenburg, A. (2012). Agroecologia, transição agroecológica e mudança ambiental. In: Brandenburg, A.; Ferreira, A. D. D. (orgs.). Agricultores agroecológicos e o ambiente rural: visões interdisciplinares. São Paulo: Annablume; CNPq; Petrobras, 2012. 
Research, Society and Development, v. 10, n. 10, e438101019008, 2021

(CC BY 4.0) | ISSN 2525-3409 | DOI: http://dx.doi.org/10.33448/rsd-v10i10.19008

Zonin, W. J. \& Neukircehn, L. (2020). Interdisciplinaridade sem fronteiras: águas, alimentos, saberes, inclusão social e produtiva nos territórios rurais da América Latina. Curitiba: CRV, 2020. 254p.

Zonin, W. J. (2007). Transição Agroecológica: Modalidades e estágios na região metropolitana de Curitiba. Tese. Doutorado em Meio Ambiente e Desenvolvimento, Universidade Federal do Paraná - Curitiba. 